\title{
Removal efficiency of fecal coliform at different type of constructed wetland systems namely VSSF, HSSF and SF
}

\author{
Jassim Hussein Abdullah Al-Maliky ${ }^{1, *}$, Abdul-Hussain Yousif Al-Adhub ${ }^{2}$, Najah Abood Hussain ${ }^{3}$ \\ Dept. of Biology, College of Science, University of Basrah, Basrah, Iraq \\ *Corresponding Author: \\ Email: marshlands2014@gmail.com
}

\begin{abstract}
The study was conducted during 2015 to evaluate removing effciency of feacal coliform form wastewater by three type of constructed wetland systems. These systems nemaly Vertical subsurface flow (VSSF), Horizontal subsarface flow (HSSF) and surface flow (SF). The total mean removal efficiency of fecal coliform after five days of treatment reached $68.43 \%$ and for each system was $70.26 \%, 68.19 \%$ and $66.69 \%$ for HSSF, VSSF and SF respectively.Also, the rsults recorded remving effciency of $55.93 \%$ when the loding rate was $25 \%$ and it reached about $63.65 \%$ when the loading rate was $50 \%$. The total mean of removal efficiency of fecal coliform achieved in April was 56.22\% while the total mean removal efficiency was $62.01 \%$ in May for the same systems. The statical analysis showed a siginficant deffriences of fecal coliform removing among resident time and system type, while, there was no significant deffriences among loading rate percenatge.
\end{abstract}

Keywords: Constructed wetland, Fecal Coliform, Horizontal subsarface flow system, Vertical subsarface flow, Surface flow.

\section{Introduction}

Human pathogens are a domestic wastewater pollutants could be contaned bacteria, protozoans, viruses and helminths, are treated in some way at constructed wetland. Fecal coliform is the main measurement form which has been used to assess treatment system for its ability to treat pathogens. ${ }^{1,2}$ Generally these organisms declined after passing through a constructed wetland. Much research done to evaluate constructed wetlands' ability to remove pathogens found differing abilities and effectiveness. Some studies indicated a reduction in pathogens of up to $57 \%, 62 \%, 98 \%$ and $87 \%$ of total coliform, fecal coliform, Giardia, cryposriduim spp. and $38 \%$ coliphage respectively. ${ }^{3,4}$ Additionally, it was also indicated that viruses of human pathogens could be removed by constructed wetland systems. ${ }^{5}$ In Morocco, a study has been conducted in order to assess the purification of municiple wastewater in semi-arid circumstances. Phragmities australis planted with reed beds at a hydrolic load around (0.86-1.44m3.d-1) achieved a removal percentage of parasitic elements between 71 to $95 \% .^{6}$ Other researchers have focused on possible pathogen removal mechanisms that have occurred in wetlands, showing incredible removal efficienty of Escherichia coli (E. coli) - up to $95 \% .^{7}$ In additon, the results of a health survey recorded some important values about the significant decline of diarrheal and hepatitis illnesses which reached about $92.5 \%$ and $40 \%$ respectively. ${ }^{8}$

\section{Materials and Methods}

The experiments were conducted at constructed wetland station at Universty of Basrah. Wastewater was provided from the main septic tank by submerged pump to be stored at storage tanks for 24 hours. Then, the three systems of constructed wetland were fed by gravity. Two loading rate percentage were dischrged into the systems $25 \%$ and $50 \%$ which equal to (162 and 324L) respectively. Waste water stay at the systems for 5 days as resident time and the samples were taken at mix time and after 5 days of treatment. At the lab, fecal coliform has been selected for measurement in this study according to colony forming unit (CFU/mL) and most probable number technique (MPN index/100 mL) of pathogenic indicators i.e. the fecal coliforms method which is described in the guidelines of Bergey's Manual of Determinative Bacteriology (Holt et al., 1994).

\section{Fecal coliform with system type}

The results in (Fig. 1) indicated the total mean and Std. deviation of fecal coliform for HSSF, SF and VSSF after five days of treatment were $1.64 \pm 0.25,2.30 \pm 0.38$ and $1.86 \pm 0.43$, while at mix, these values were $2.46 \pm 0.46,3.13 \pm 0.12$ and $2.76 \pm 0.43$ respectively. The total mean for SW was $5.36 \pm 0.23$, whereas for TW was $1.94 \pm 0.06$. The highest value of 5.68 was recorded for SW and lowest of 1.30 recorded in day five in HSSF and VSSF. Statistical analysis showed that there were significant differences in FC among retention time in days at $\mathrm{P} \leq 0.05$. With regard to system type also showed significant differences in that parameter. On the other hand, the interaction between retention time * system type showed no significant differences at $\mathrm{P} \leq 0.05$. 


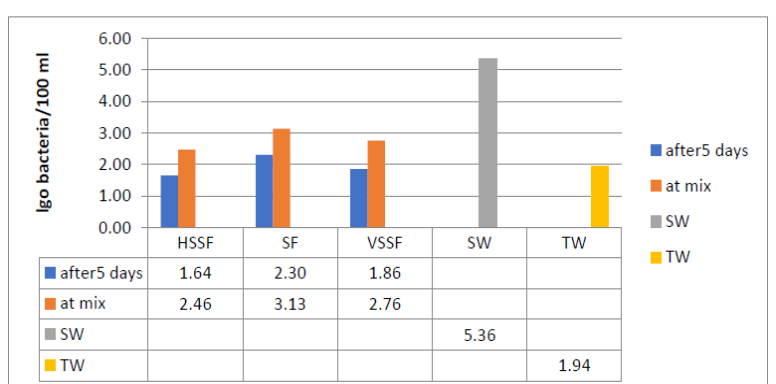

Fig. 1: Fecal coliform with time in days

The total mean removal efficiency of fecal coliform after five days of treatment reached $68.43 \%$. Preformance systems of removal efficiency was $70.26 \%$, $68.19 \%$ and $66.69 \%$ for HSSF, VSSF and SF respectively, while these values were $48.22 \%, 42.67 \%$ and $43.22 \%$ for the same systems at mix time. The maximum removal efficiency of $75.39 \%$ was recorded at HSSF after five day, while the lowest removal efficiency was about $40.79 \%$ glanced at SF at mix time (Fig. 2).

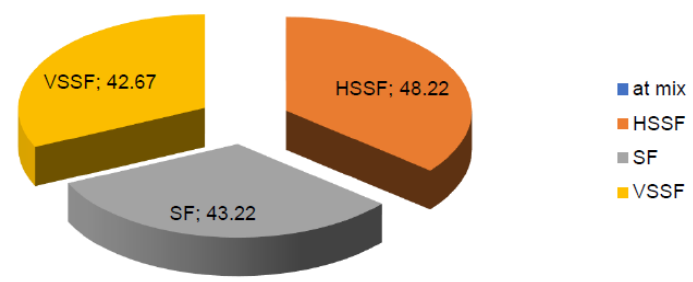

Fig. 2: System's removal efficiency at mix time

It is clear to see that all systems did well to remove high percentage of fecal coliform, however, HSSF and VSSF were better for removing fecal coliform compared with SF.

\section{Fecal coliform with loading rate}

The results in (Fig. 3) show the total mean and Std. deviation of fecal coliform with $25 \%$ and $50 \%$ loading rate percentage which were $2.43 \pm 0.61$ and $2.13 \pm 0.59$. This level was $5.36 \pm 0.23$ for SW and $1.94 \pm 0.06$ for TW. The lowest feacal coliform values was 1.30 recorded at HSSF and VSSF when the loading rate was $50 \%$ and the highest feacal coliform level was 5.68 recorded for SW when the loading rate was $25 \%$.

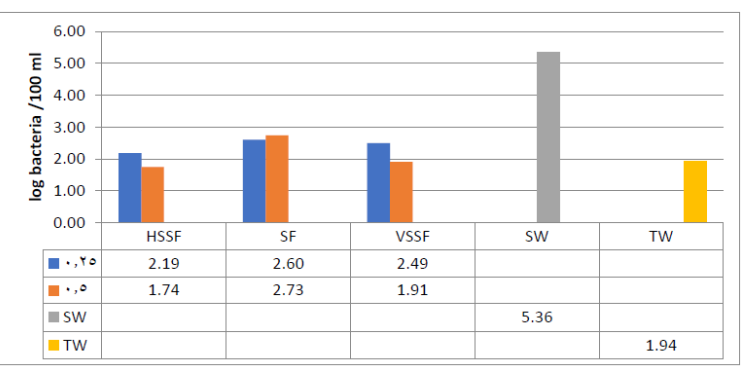

Fig. 3: Fecal coliform with loading rate in stable operation method
Statistical analysis by using T-test confirmed that there were no significant differences in FC between loading rate percentage at $\mathrm{P} \leq 0.05$.

The removal efficiency of fecal coliform were achieved with both loading was $55.93 \%$ when the loding rate was $25 \%$. Also, the results were better when the loading rate was $50 \%$ as it reached about $63.65 \%$. It were $62.58 \%, 53.93 \%$ and $51.49 \%$ for HSSF, VSSF and SF for the first loading rate (Fig. 4).

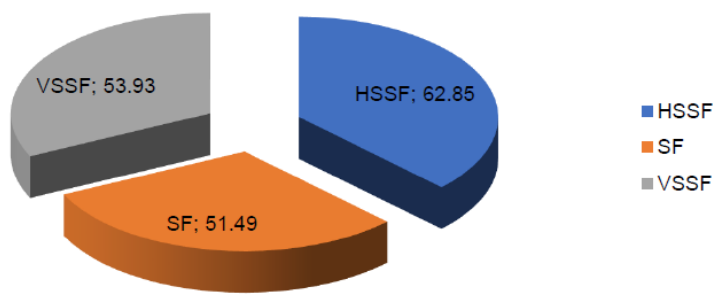

Fig. 4: FC removal efficiency when the loading rate $25 \%$

Also, it were $68.50 \%, 64.86 \%$ and 41.88 for the systems above when the loading rate was $50 \%$ (Fig. 5).

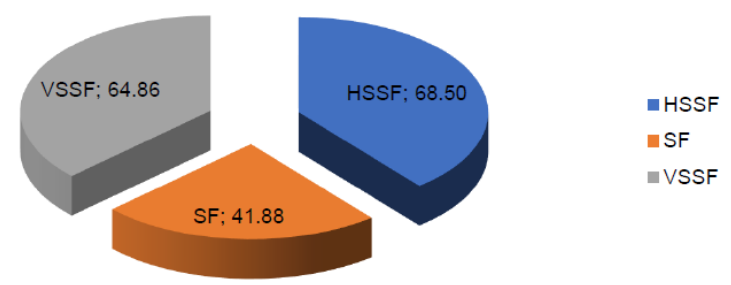

Fig. 5: FC removel efficiency when the loading rate $\mathbf{5 0 \%}$

\section{Fecal coliform with months}

The results in (Fig. 6) indicated that the total mean and Std. deviation of fecal coliform for the two months April and May were 2.43 \pm 0.61 and $2.31 \pm 0.59$ respectively. The highest value was 5.68 recorded for SW and the lowest value of 1.30 was achieved in May at HSSF and VSSF, while the lowest value of 1.40 was recorded in April at HSSF. Statistical analysis confirmed that there were no significant differences in FC between months at $\mathrm{P} \leq 0.05$. Whereas, there were significant differences of FC among system type at the same level.

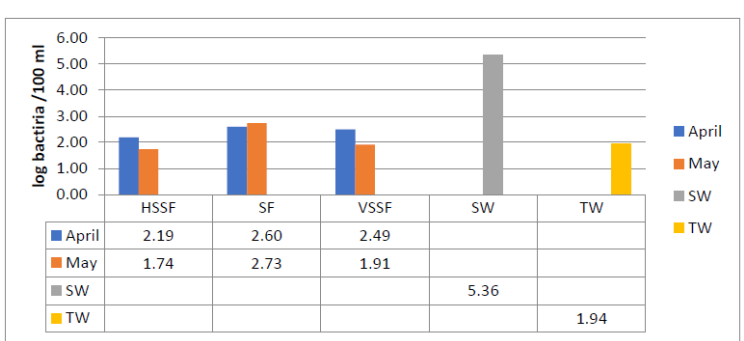

Fig. 6: Fecal coliform with months 
The total mean of removal efficiency of fecal coliform achieved in April was $56.22 \%$ while these values were $62.85 \%, 53.22 \%$ and $51.49 \%$ for $\mathrm{HSSF}$, VSSF and SF respectively (Fig. 7), while the total mean removal efficiency was $62.01 \%$ in May for the same systems (Fig. 8).
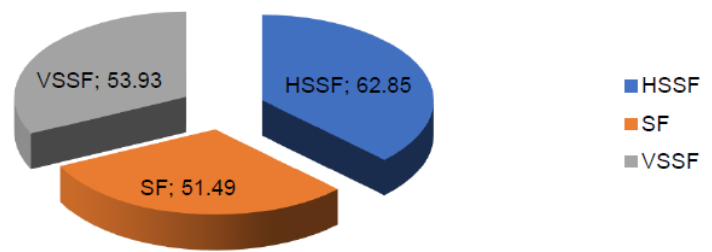

nSF

IVSS

Fig. 7: FC removal efficiency in April

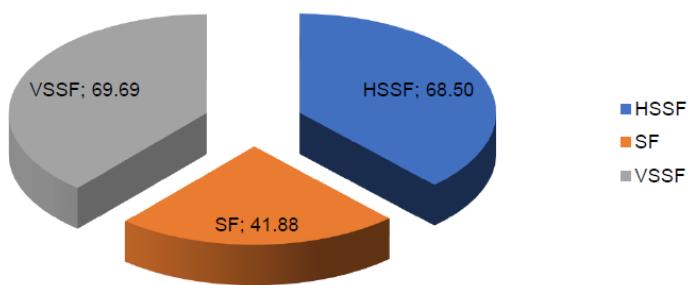

Fig. 8: FC removal efficiency in May

\section{Discussion}

The results in Fig. 1 illustrate that pathogens can be effectively removed using different constructed wetland systems. The removal efficiency (Fig. 2) of fecal coliform after five days of treatment reached $66.69 \%$, $68.19 \%$ and $70.20 \%$ within the SF, VSSF and HSSF systems respectively.

Pathogens can be removed through many constructed wetland mechanisms. These include chemical (affected by other microorganisms or plants toxins and oxidative destruction), physical (aggregation and adsorption, filtration and sedimentation) and biological (natural death, consumed by lytic bacteria, protozoa and bacteriophages). Nevertheless, sedimentation is still the primary process by which constructed wetlands can treat pathogens. ${ }^{4}$ Also, UV radiation is another factor in the removal of pathogenic microorganisms [9]. Generally, it has been reported that the removal efficiency efficiency of fecal bacteria normally exceeds $85 \%$ and more for fecal coliform. ${ }^{10}$ The results which have been found by ${ }^{11}$ showed that removal efficiency of total coliform at a pilot scale constructed wetland were about $96.91 \%$ for VFCWs compared to $92.71 \%$ for HFCWs. The main reason for the higher ability of VFCWs to remove pathogens is related to a high level of oxygen which can be found within this kind of system which increases the abundance of natural predators, ${ }^{12}$ while the opposite situation might occur at HFCWs as a result of saturated circumstances and temperature drops. ${ }^{10}$ The results of the present study found that slightly opposite situation had occurred as HSSF ability of removing fecal coliform was slightly better than within the VSSF system. Because a pilot scale project perhaps doesn't recreate identical scenarios to those found in nature, this may be the reason behind these differences. Also the period of retention time could have significant impacts on the removal ability as it is clear that the performance of the two systems after five days of treatment became very similar. More studies are needed on this to focus on the factors which could affect pathogen removal within constructed wetland systems.

Regarding the loading rate percentage, with the exception of SF removal efficiency, fecal coliform removal results were contrary to expectation with a $50 \%$ loading rate resulting in better results than when the loading rate was 25\% (Fig. 3, 4 and 5). The reason behind this is not clear, however, it could be due to special circumstances inside each system. The results could provide a good indicator that even with a high loading rate, the system's ability to remove fecal coliform is still high.

The results in figure 7 and 8 showed an increase in all systems' removal efficiency during May compared to April, with the excpetion of the SF system. It was found that the temperature particularly within the summer months which is normally high could remove a high rate of pathogens by natural die-off and inactivation. ${ }^{9}$ So, a high temperature in May positively affected the HSSF and VSSF systems, and increased their ability to remove fecal coliform.

\section{Conclusion}

Fecal coliform could be effectively removed by constructed wetland systems. Resident time and type of system can play a vital role of removal process. The study showed high removing efficiency of fecal coliform even with double loading rate percentage to about $50 \%$ of its volume capacity.

\section{References}

1. IWA, S.G.W., Constructed wetlands for pollution control: processes, performance, design and operation. 2001, Iwa: Iwa Publishing. 171.

2. ElZeina, Z., A. Abdoub, and I. AbdAlGawadc, Constructed wetlands as a sustainable wastewater treatment method in communities. Procedia Environmental Sciences, 2016. 34:p. 605-17.

3. Stottmeister, U., et al., Effects of plants and microorganisms in constructed wetlands for wastewater treatment. Biotechnology advances, 2003.22(1)(1):p. 93117.

4. Karim, M.R., et al., The persistence and removal of enteric pathogens in constructed wetlands. Water research, 2004. 38(7): p. 1831-7.

5. Juwarkar, A.S., et al., Domestic wastewater treatment through constructed wetland in India. Water Science and Technology, 1995. 32(3):p. 291-4.

6. Mandi, L., K. Bouhoum, and N. Ouazzani, Application of constructed wetlands for domestic wastewater treatment in an arid climate. Water Science and Technology, 1998.38(1):p. 379-87.

7. Greenway, M., The role of constructed wetlands in secondary effluent treatment and water reuse in 
subtropical and arid Australia. Ecological engineering, 2005. 25(5): p. 501-9.

8. Hunter, G., constructed wetlands: design, construction and maintenance considerations, in Weltland treatment systems operation and maintenance checklist, A. r. council, Editor. 2015: Sydney. p. 223-50.

9. Weber, K.P. and R.L. Legge, Pathogen removal in constructed wetlands. Wetlands: Ecology, Conservation and Restoration, 2008:p. 176-211.

10. Vymazal, J., Removal of enteric bacteria in constructed treatment wetlands with emergent macrophytes: a review. Journal of environmental science and health, 2005. 40(67): p. 1355-67.

11. Zurita, F., et al., Seeking a way to promote the use of constructed wetlands for domestic wastewater treatment in developing countries. Water Science and Technology, 2011. 63(4):p. 654-9.

12. Wand, H., et al., Removal of bacteria by filtration in planted and non-planted sand columns. Water research, 2007. 41(1): p.159-67. 